\title{
Response to the letter by Udo Bonnet
}

We appreciate your interest in our article ${ }^{1}$ and agree that the two cases cited meet an acceptable diagnostic threshold for cannabinoid hyperemesis syndrome (CHS). These cases had long-term follow-up and improvement after cannabis abstinence, implying that heavy cannabis use contributed to their recurrent vomiting. However, we would like to restate our position that $\mathrm{CHS}$ is a subset of cyclic vomiting syndrome (CVS), triggered by chronic, heavy cannabis exposure. ${ }^{2}$ If cannabis were the sole cause of hyperemesis, we would expect more CHS-afflicted individuals, especially given its widespread use. However, only 7 cases met Rome IV criteria for CHS in a population-based US study. ${ }^{3}$ In another recent investigation, $41 \%$ of 140 CVS patients reported current cannabis use ${ }^{4} ; 50 / 57$ (88\%) cannabis users abstained for $>1$ month but only one individual experienced resolution of hyperemesis and was the only patient who met Rome criteria for $\mathrm{CHS}$. Of note, this patient remains symptom-free despite resuming cannabis with higher cannabidiol (CBD). ${ }^{4}$

These rare cases of purported CHS raise important questions. Why do most chronic cannabis users not develop hyperemesis? Are there genetic variants that predispose them to vomit? The endocannabinoid system plays an important role in regulating nausea and vomiting. Cannabis acts primarily on cannabinoid receptor type 1 (CB1R). We reported both increased and decreased risk of CVS in individuals with different CBR1 gene polymorphisms. ${ }^{5}$ It is plausible that genetically susceptible individuals develop symptoms when exposed to triggers such as cannabis (particularly high potency products) and stress in complex gene-environment interactions.

Cyclic vomiting syndrome and CHS are phenotypically similar except for chronic cannabis use. The hot-water bathing behavior is not pathognomonic of CHS and is seen in $~ 40 \%$ of CVS patients who do not use cannabis. Future studies to understand the effects of chronic cannabis in vomiting disorders are warranted, given increasing cannabis legalization.

We agree that gastric emptying can be delayed by cannabis and is accelerated in nearly $60 \%$ of CVS patients. ${ }^{6,7}$ However, abnormalities are not universal in CVS or CHS, and hyperemesis does not clearly improve with therapies which slow or stimulate gastric emptying. Emptying impairments may be markers of autonomic dysfunction and probably do not cause symptoms in either condition.

In summary, we reiterate that CHS is likely a subset of CVS and chronic cannabis use can trigger symptoms in genetically predisposed individuals. This is supported by the literature and our collective experience caring for these patients.

Thangam Venkatesan ${ }^{1}$ David J. Levinthal ${ }^{2}$
B. U. K. $\mathrm{Li}^{3}$
William. L. Hasler
(iD

${ }^{1}$ Division of Gastroenterology and Hepatology, The Medical College of Wisconsin, Milwaukee, Wisconsin

${ }^{2}$ Department of Medicine, Division of Gastroenterology, Hepatology, and Nutrition, University of Pittsburgh Medical Center, Pittsburgh,

Pennsylvania

${ }^{3}$ Medical College of Wisconsin, Milwaukee, Wisconsin

${ }^{4}$ Department of Gastroenterology, University of Michigan Health

System, Ann Arbor, Michigan

Correspondence

Thangam Venkatesan, Division of Gastroenterology and Hepatology, The Medical College of Wisconsin, Milwaukee, WI.

Email: tvenkate@mcw.edu

\section{ORCID}

Thangam Venkatesan (iD https://orcid.org/0000-0002-8095-7456

William. L. Hasler iD https://orcid.org/0000-0002-6158-2871

\section{REFERENCES}

1. Venkatesan T, Levinthal DJ, Li B, et al. Role of chronic cannabis use: cyclic vomiting syndrome vs cannabinoid hyperemesis syndrome. Neurogastroenterol Motil. 2019;31(suppl 2):e13606.

2. Hasler WL, Levinthal DJ, Tarbell SE, et al. Cyclic vomiting syndrome: pathophysiology, comorbidities, and future research directions. Neurogastroenterol Motil. 2019;31(suppl 2):e13607.

3. Aziz I, Palsson OS, Whitehead WE, Sperber AD, Simren M, Tornblom H. Epidemiology, clinical characteristics, and associations for Rome IV functional nausea and vomiting disorders in adults. Clin Gastroenterol Hepatol. 2019;17(5):878-886.

4. Venkatesan T, Banerjee A, Hillard C, Lisdahl KM. Patterns of cannabis use in patients with cyclic vomiting syndrome. Clin Gastroenterol Hepatol. 2019.

5. Wasilewski A, Lewandowska U, Mosinska P, et al. Cannabinoid receptor type 1 and mu-opioid receptor polymorphisms are associated with cyclic vomiting syndrome. Am J Gastroenterol. 2017;112:933-939.

6. McCallum RW, Soykan I, Sridhar KR, Ricci DA, Lange RC, Plankey MW. Delta-9-tetrahydrocannabinol delays the gastric emptying of solid food in humans: a double-blind, randomized study. Aliment Pharmacol Ther. 1999;13:77-80.

7. Venkatesan T, Levinthal DJ, Tarbell SE, et al. Guidelines on management of cyclic vomiting syndrome in adults by the American neurogastroenterology and motility society and the cyclic vomiting syndrome association. Neurogastroenterol Motil. 2019;31(suppl 2):e13604. 